ORIGINAL ARTICLE

\title{
From insecure to secure employment: changes in work, health, health related behaviours, and sickness absence
}

\author{
M Virtanen, M Kivimäki, M Elovainio, J Vahtera, J E Ferrie
}

Occup Environ Med 2003;60:948-953

See end of article for authors' affiliations

......................

Correspondence to:

Dr M Virtanen, Finnish

Institute of Occupational

Health, Department of

Psychology,

Topeliuksenkatu 41 a A,

FIN-00250 Helsinki,

Finland;

marianna.virtanen@

occuphealth.fi

Accepted

17 December 2002

\begin{abstract}
Aims: To determine whether change in employment status (from fixed term to permanent employment) is followed by changes in work, health, health related behaviours, and sickness absence.

Methods: Prospective cohort study with four year follow up. Data from 4851 (710 male, 4141 female) hospital employees having a fixed term or permanent job contract on entry to the study were collected at baseline and follow up.

Results: At baseline, compared to permanent employees, fixed term employees reported lower levels of workload, job security, and job satisfaction. They also reported greater work ability. All fixed term employees had a lower rate of medically certified sickness absence at baseline. Baseline rate ratios for those who remained fixed term were 0.64 (95\% $\mathrm{Cl} 0.55$ to 0.75$)$, and were 0.50 (95\% $\mathrm{Cl} 0.34$ to 0.75 ) for those who later became permanent. Continuous fixed term employment was not associated with changes in the outcome measures. Change from fixed term to permanent employment was followed by an increase in job security, enduring job satisfaction, and increased medically certified sickness absence (compared to permanent workers rate ratio $0.96(95 \% \mathrm{Cl} 0.80$ to 1.16)). Other indicators of work, health, and health related behaviours remained unchanged.

Conclusion: Receiving a permanent job contract after fixed term employment is associated with favourable changes in job security and job satisfaction. The corresponding increase in sickness absence might be due to a reduction in presenteeism and the wearing off of health related selection.
\end{abstract}

n the European Union, contingent employment accounts for $12-15 \%$ of paid employment. Research suggests contingent (fixed term or temporary) employment to be associated with less favourable work characteristics, ${ }^{1}$ but studies of associations between contingent employment and health have produced inconsistent results. In some studies, non-permanent employees have reported lower work stress, ${ }^{2}$ better self rated health, ${ }^{3}$ less somatic complaints, ${ }^{5}$ and equal $^{4}$ or less prevalence of chronic diseases, ${ }^{3}$ and equal psychological wellbeing ${ }^{4}$ compared with permanent employees. However, non-permanent employment has also been associated with higher role ambiguity, ${ }^{5}$ lower job satisfaction, ${ }^{2}$ and higher psychological distress. ${ }^{36}$ Perceived job insecurity has been found to be a stressor among employees without permanent job contracts. ${ }^{357}$ Evidence from permanent employees suggests that job insecurity may have adverse effects on job satisfaction ${ }^{8}$ and several health indicators. ${ }^{9-14}$ Job insecurity has also been associated with neglect of oneself and failure to consult a physician for fear of missing work. ${ }^{9}$

Fixed term and temporary employment have been associated with a lower rate of sickness absences than permanent employment, ${ }^{2}{ }^{4}$ and fixed term workers seem to be present at work despite illness. ${ }^{4}$ Other findings indicate no differences in self reported sickness absence or in being present despite illness when fixed term employees were compared to permanent ones. ${ }^{215} \mathrm{Job}$ insecurity, in turn, has been associated with an increased risk of long term sickness absence among permanent employees, ${ }^{16-19}$ although at least three studies have documented the reverse association. ${ }^{16} 2021$ There appears to be no consistent relation between job insecurity and health related behaviours such as smoking or alcohol consumption. ${ }^{9-14}$

There is a lack of longitudinal research on these issues and inconsistencies in prior evidence may partially be due to limitations in study designs and inability to determine the temporal order between constructs. One way to address this problem would be to examine the extent to which change in employment status is followed by changes in work and health indicators. Thus, the aim of the present study was to determine whether moving from a fixed term contract to a permanent post is followed by a change in work perceptions, health, health related behaviours, and sickness absence.

\section{METHODS}

\section{Study context}

In the public healthcare sector in Finland between 1990 and 1995, the proportion of employees with a fixed term employment contract rose from $15 \%$ to $21 \% .^{22}$ At the same time the unemployment rate rose from $3 \%$ to $15 \%$, being $11 \%$ at the time of the study, which indicated competition for jobs. ${ }^{23}$ Fixed term employment as a voluntary choice in the public healthcare sector was rare: $85-88 \%$ of fixed term employees reported having this form of job contract because few permanent posts were available and open. ${ }^{22}$ In the late 1990s, about $10 \%$ of fixed term hospital employees annually received a permanent contract. ${ }^{24}$

\section{Participants}

To achieve a sample including about 100 employees who change from fixed term to permanent employment during a two year follow up period, we chose the total personnel of nearly 5000 employees of two hospital districts as the target population of this study.

These two hospital districts were participating in a project, "Work and Health in Finnish Hospital Personnel", coordinated by the Finnish Institute of Occupational Health. In this area there was one university teaching hospital, one central hospital, and eight regional hospitals, which provided specialised healthcare for 614000 inhabitants (12\% of the total Finnish population). Approval of the Ethics Committee 
Main messages

- Fixed term employees had higher job insecurity, but they took less medically certified sick leave than their colleagues with permanent job contracts.

- Receiving a permanent job contract after fixed term employment was associated with an increase in job security and enduring job satisfaction as well as an increase in medically certified sickness absence. No change was observed in health, health habits, and work characteristics.

- Receiving a permanent job seems to remove one of the "presence factors" that characterise fixed term employment. Increase in sickness absence may also be due to the wearing off of health related selection.

of the Finnish Institute of Occupational Health was obtained for this study.

A cohort of all 4851 employees (710 male, 4141 female) having at least 180 days job contract each year between 1997 and 2000, was derived from the employers' registers. They were classified into the following three groups: (1) permanent employment each year ( $\mathrm{n}=4247 ; 88 \%$ ); (2) fixed term employment in 1997-98, changing to permanent employment between July 1998 and June 1999 (n = 96; 2\%); (3) fixed term employment each year $(\mathrm{n}=508 ; 10 \%)$.

A self completion questionnaire was sent to the whole cohort at the beginning of 1998. Of the 4851 employees, 3910 $(81 \%)$ responded to the questionnaire. Two years later, 3143 of those also responded to the follow up questionnaire. A total of $65 \%$ of the study cohort responded to both questionnaires. Of these, 2806 (89\%) were permanent, 53 (2\%) fixed term to permanent, and 284 (9\%) fixed term employees. None of the fixed term to permanent employees had a part time job, but $2.7 \%$ of the permanent and $10.2 \%$ of the fixed term employees worked part time.

\section{Measures}

Information on employees' age, sex, type of employment, the number of contracted days each year, occupational title, and the number of medically certified ( $>3$ days) sickness absence spells, were obtained from the employers' registers. Information on workload, job insecurity, job satisfaction, health, and health related behaviours were obtained from the questionnaires.

Each participant's sickness absence record between 1 January 1997 and 31 December 2000, was obtained from the employers' registers, which documents and lists the start and end dates of every sick leave period for each employee. In accordance with existing regulations, each sick leave certificate, irrespective of the place of issue, must be forwarded to these registers. Maternity leave and absence due to caring for a sick child is not counted as sickness absence. Correction was made for overlapping and duplicated spells of sickness absence. Baseline sickness absence was calculated as the number of medically certified spells of sickness absence between 1 January 1997 and 31 December 1997. Sickness absence at follow up comprised spells of absence between 1 January 1999 and 31 December 2000. The number of contracted days at baseline and follow up represented "days at risk", from which the number of days absent from work for reasons other than sickness was subtracted.

Occupational titles, expressed as five digit Statistics Finland codes, were used to link information on income to the data set. Average monthly income figures, calculated
Policy implications

- To improve the quality of work life it is important to reduce job insecurity among employees with nonpermanent employment contracts.

- The issue of health selection should be considered in the employment policy to reduce the widening of socioeconomic differences in health.

separately for men and women by occupational title, were obtained from Statistics Finland.

Workload was measured by using the four item Nurse Stress Index, ${ }^{25} 26$ asking how much the following things have disturbed, worried, or stressed the subject during the past six months: "Time pressures and deadlines"; "I have too little time to do what is expected of me"; "Shortage of essential resources (for example, staff)"; and "I spend my time 'fighting fires' rather than working to a plan" (from $1=$ seldom or ever to $5=$ very often or constantly). The measure was a simple sum of these five point response scale items (Cronbach's $\alpha=0.84$ ).

Job insecurity was assessed by two questions, which estimate the threat of long term unemployment or dismissal ${ }^{27}$ (from $1=$ very little to $5=$ very much). A simple sum of job insecurity was calculated (Cronbach's $\alpha=0.93$ ).

Job satisfaction was assessed by an overall measure of satisfaction consisting of 14 items from Hackman and Oldham's ${ }^{28}$ Job Diagnostic Survey. This scale assesses satisfaction with employment security, pay, co-workers, supervision, and personal growth. A seven point scale (from $\mathrm{l}=$ extremely dissatisfied to $7=$ extremely satisfied) was used to rate the items (Cronbach's $\alpha=0.85$ ).

The number of diagnosed chronic diseases was derived from a list of 14 common diseases (for example, asthma, rheumatoid arthritis, diabetes, cardiovascular disease). From this information, a summed score was calculated. The prevalence of diagnosed diseases has been shown to predict sickness absence in earlier studies. ${ }^{179}$

Work ability is a single item measure in which the respondents provide an overall assessment of their work ability on a 10 point scale $(0=$ not able to work at all, $10=$ my best work ability ever). ${ }^{30} 31$

Minor psychiatric morbidity was measured by the 12 item version of Goldberg's $\mathrm{s}^{32}$ General Health Questionnaire (GHQ12), which produces results comparable to the longer versions of the GHQ. ${ }^{33}$ Respondents rate how much they were affected by each of the 12 symptoms of distress over the previous few weeks $(0=$ not at all, $1=$ the same as usual, $2=$ rather more than usual, or $3=$ much more than usual). In the current study, GHQ-12 was used as a summed score (range $0-12)$ of the dichotomised items representing $(0=$ no distress, $1=$ distress) (Cronbach's $\alpha=0.90)$.

Alcohol intake (g/week), smoking (no. of cigarettes/day), and body mass index (BMl) were derived from survey responses.

\section{Statistical analysis}

The dispersion of medically certified sickness absence spells followed the assumptions for Poisson models. Thus, we determined the rate ratios and their $95 \%$ confidence intervals for sickness absence by Poisson regression analysis.. ${ }^{34}$ Analyses of variance were used for the other measured variables. Tests of heterogeneity for employment status group differences between baseline and follow up were tested using the repeated measures analyses of variance procedure to determine the interaction between time and employment 
status. For the Poisson models we used the GENMOD procedure in the SAS program package.

\section{RESULTS}

\section{Sample attrition}

Regarding occupation, study participants were very similar to the eligible population. The most common occupation was nurse $(52 \%$ of the respondents, $47 \%$ of the eligible population, respectively). Fourteen per cent of the respondent (16\% of the eligible population) worked in maintenance and cleaning, $13 \%$ of the respondents $(15 \%$ of the eligible population) were laboratory and $x$ ray personnel, $12 \%$ of the respondents ( $12 \%$ of the eligible population) were administrative staff, $5 \%$ of the respondents $(7 \%$ of the eligible population) were physicians, and $4 \%$ of the respondents (3\% of the eligible population) other professionals. Thus, nurses were over-represented, while employees in maintenance and cleaning, administrative staff, physicians, and other professionals were somewhat underrepresented among the respondents. As shown in table 1, men and workers with lower income were also slightly under-represented.

Among the eligible population, change from fixed term to permanent employment was more common in men than in women $\left(24 \%\right.$ in men $v 15 \%$ in women, $\chi^{2}=5.22, \mathrm{df}=1$, $\mathrm{p}=0.022)$, in higher income class than in lower income class $\left(19 \% v 13 \%, \chi^{2}=4.39, \mathrm{df}=1, \mathrm{p}=0.036\right)$, and in physicians than in other occupational groups (33\% $v 14 \%$, $\left.\chi^{2}=14.31, \mathrm{df}=1, \mathrm{p}<0.001\right)$.

Of the total cohort, $65 \%$ (67\% in permanent, $56 \%$ in fixed term, and $55 \%$ in fixed term to permanent employees) responded to both questionnaires. The respondents did not differ from the eligible population in sex, age, or number of contracted days. Employees in the lower income group were under-represented among fixed term respondents $(40 \%$ in respondents $v 47 \%$ in the eligible population) and among permanent respondents $(48 \% \vee 51 \%)$, and slightly overrepresented in fixed term to permanent respondents $(38 \% v$ $35 \%)$. Physicians were under-represented among fixed term to permanent employees $(27 \% v 33 \%)$ (these figures are not shown in table 1 ).

\section{Baseline differences}

At baseline, there were significant differences in terms of workload, job insecurity, job satisfaction, and work ability (table 2). Permanent employees reported the highest workload, lowest job insecurity and highest job satisfaction, while fixed term employees had the highest insecurity. Additionally, fixed term employees reported lower workload, lower job satisfaction, and higher work ability than permanent employees. Fixed term to permanent employees differed from permanent ones in terms of higher job insecurity only. There were no statistically significant associations between employment status and number of chronic diseases or minor psychiatric morbidity. With regard to health related behaviours (alcohol intake, smoking, and BMI) no differences were found between the groups.

As fig 1 shows, compared to permanent employees, fixed term to permanent workers had a $50 \%$, and fixed term employees a $36 \%$, lower medically certified sickness absence rate at baseline (all p $<0.001$ ). Mean annual number (SE) of sickness absence spells (adjusted for age, sex, and income) was $0.70(0.02)$ in permanent employees, $0.41(0.11)$ in fixed term to permanent ones, and $0.46(0.05)$ in fixed term employees, respectively.

\section{Changes at follow up}

During the follow up period, job insecurity decreased among fixed term to permanent employees. Job satisfaction decreased in permanent and fixed term workers, but not in fixed term to permanent employees (table 3 ). No interaction between time and employment status was found for health (number of diagnosed chronic diseases, work ability, and minor psychiatric morbidity), or health related behaviours (alcohol intake, smoking, and BMI). Overall, the number of diagnosed chronic diseases had increased and work ability had decreased in all employees in a similar way.

With regard to medically certified sickness absence spells at follow up, there was no longer a significant difference between fixed term to permanent employees and permanent employees, but fixed term employees still had a significantly lower $(26 \%, p<0.001)$ absence rate than permanent employees (fig 1). Mean annual number (SE) of sickness absence spells (adjusted for age, sex, and income) was 0.83 $(0.02)$ in permanent employees, $0.81(0.11)$ in fixed term to permanent ones, and $0.63(0.05)$ in fixed term employees, respectively.

\section{DISCUSSION}

This is apparently the first study to determine the association between a change in employment status-from fixed term to permanent employment-and subsequent change in several

\begin{tabular}{|c|c|c|c|c|c|}
\hline \multirow[b]{2}{*}{ Characteristics } & \multirow[b]{2}{*}{$\begin{array}{l}\text { Eligible } \\
\text { population } \\
\text { ( } \mathrm{n}=4851 \text { ) }\end{array}$} & \multicolumn{4}{|l|}{ Respondents } \\
\hline & & All $(n=3143)$ & $\begin{array}{l}\text { Fixed term } \\
(\mathrm{n}=284)\end{array}$ & $\begin{array}{l}\text { Fixed term to } \\
\text { permanent } \\
(\mathrm{n}=53)\end{array}$ & $\begin{array}{l}\text { Permanent } \\
(\mathrm{n}=2806)\end{array}$ \\
\hline \multicolumn{6}{|l|}{ Sex, n (\%) } \\
\hline Male & $710(15)$ & 347 (11) & $23(8)$ & $9(17)$ & 315 (11) \\
\hline Female & 4141 (85) & 2796 (89) & $261(92)$ & $44(83)$ & 2491 (89) \\
\hline \multicolumn{6}{|l|}{ Age group, n (\%) } \\
\hline $23-34$ & $503(10)$ & $305(10)$ & $96(34)$ & $18(34)$ & $191(7)$ \\
\hline $35-45$ & $1802(37)$ & 1197 (38) & $119(42)$ & $21(40)$ & 1057 (38) \\
\hline $46-61$ & 2546 (53) & 1641 (52) & 69 (24) & $14(26)$ & $1558(55)$ \\
\hline \multicolumn{6}{|l|}{ Income ${ }^{*}, \mathrm{n}(\%)$} \\
\hline 1 (low) & $2414(50)$ & $1462(47)$ & $113(40)$ & $20(38)$ & $1329(48)$ \\
\hline 2 (high) & $2388(50)$ & $1653(53)$ & $170(60)$ & $33(62)$ & 1450 (52) \\
\hline $\begin{array}{l}\text { Number of contracted days } \\
\text { at baseline, mean (SD) }\end{array}$ & $310.6(20.2)$ & 310.9 (19.3) & $307.0(43.5)$ & $312.1(26.8)$ & 311.2 (14.5) \\
\hline $\begin{array}{l}\text { Number of contracted days } \\
\text { at follow up, mean (SD) }\end{array}$ & $617.9(31.9)$ & $618.7(27.8)$ & $628.4(44.9)$ & $625.8(27.1)$ & $617.54(25.3)$ \\
\hline
\end{tabular}

Figures are numbers (percentage) and means (SD) for the total cohort and respondents in both surveys. *Cut off points were 1930 per month in men and 1717 per month in women. Numbers are lower due to missing information. 
Table 2 Differences in means $(95 \% \mathrm{Cl})$ at baseline for work characteristics, health indicators, and health related behaviours by employment status (in all cases the mean difference for permanent employment was set to 0.00 )*

\begin{tabular}{|c|c|c|c|c|}
\hline & Fixed term & $\begin{array}{l}\text { p value for } \\
\text { difference }\end{array}$ & Fixed term to permanent & $\begin{array}{l}\text { p value for } \\
\text { difference }\end{array}$ \\
\hline \multicolumn{5}{|l|}{ Work } \\
\hline $\begin{array}{l}\text { Workload } \\
\text { Job insecurity }\end{array}$ & $\begin{array}{l}-0.21(-0.33 \text { to }-0.09) \\
1.79(1.68 \text { to } 1.91)\end{array}$ & $\begin{array}{l}<0.001 \\
<0.001\end{array}$ & $\begin{array}{r}-0.23(-0.49 \text { to } 0.04) \\
0.99(0.75 \text { to } 124)\end{array}$ & $\begin{array}{r}0.104 \\
<0.001\end{array}$ \\
\hline Job satisfaction & $-0.32(-0.43$ to -0.21$)$ & & $-0.10(-0.33$ to 0.13$)$ & 0.540 \\
\hline \multicolumn{5}{|c|}{$-0.021-0.4010-0.211<<0.001$} \\
\hline $\begin{array}{l}\text { No. of diagnosed } \\
\text { chronic diseases }\end{array}$ & $-0.06(-0.22$ to 0.10$)$ & 0.659 & $-0.03(-0.38$ to 0.31$)$ & 0.970 \\
\hline Work ability & $0.22(0.04$ to 0.39$)$ & 0.013 & $0.37(-0.01$ to 0.76$)$ & 0.060 \\
\hline $\begin{array}{l}\text { Minor psychiatric } \\
\text { morbidity }\end{array}$ & $0.06(-0.38$ to 0.50$)$ & 0.948 & $-0.06(-1.02$ to 0.90$)$ & 0.989 \\
\hline \multicolumn{5}{|l|}{ Health related behaviours } \\
\hline Alcohol intake (g/week) & $-6.14(-20.60$ to 8.32$)$ & 0.567 & $-17.90(-49.21$ to 13.41$)$ & 0.361 \\
\hline $\begin{array}{l}\text { Smoking (no. of } \\
\text { cigarettes/day) }\end{array}$ & $0.04(-0.63$ to 0.70$)$ & 0.990 & $-0.86(-2.29$ to 0.58$)$ & 0.329 \\
\hline BMI & $0.23(-0.35$ to 0.81$)$ & 0.607 & $-0.42(-1.69$ to 0.84$)$ & 0.702 \\
\hline
\end{tabular}

work characteristics, health, and health related indicators. Our findings indicate that change in employment status is followed by an increase in job security, job satisfaction, and medically certified sickness absence. However, no change in health indicators or health related behaviours became evident when the groups of fixed term, fixed term to permanent, and permanent employees were compared.

In general, employees with fixed term job contracts had higher job insecurity and lower job satisfaction than permanent employees, a finding that is in line with earlier research. ${ }^{235}$ However, there were no differences in health (number of chronic diseases and minor psychiatric morbidity) between the groups at baseline. This is in accordance with some earlier cross sectional findings on perceived health and wellbeing among contingent workers, ${ }^{2-5}$ but not with others. ${ }^{6-7}$

No changes in health related behaviours were found in fixed term employees, despite their exposure to continued

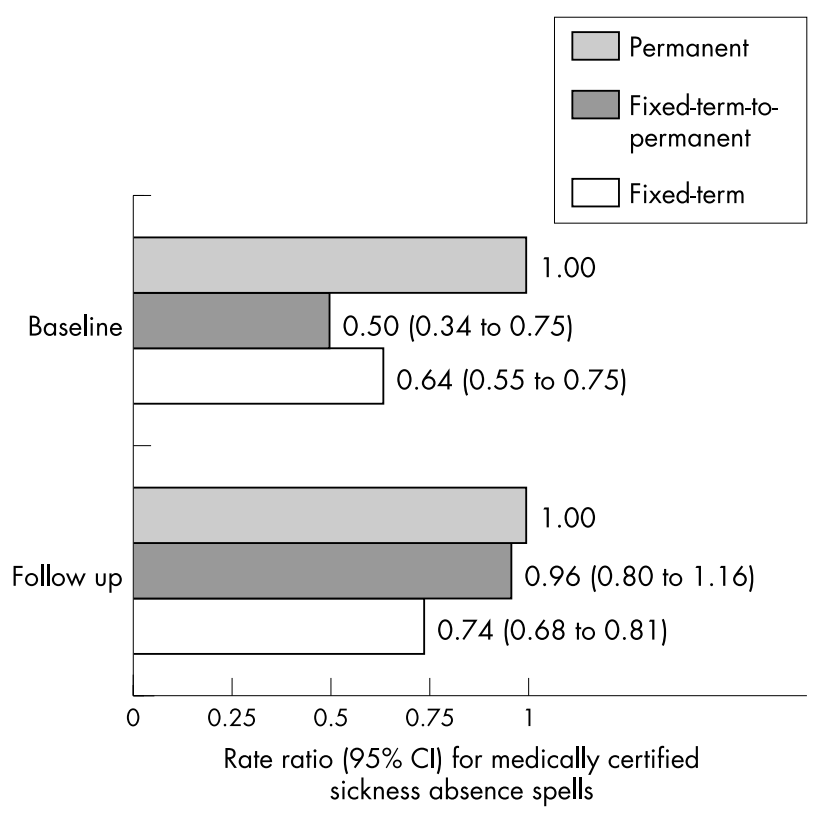

Figure 1 Rate ratio $(95 \% \mathrm{Cl})$ for medically certified sickness absence spells at baseline and follow up by employment status. Adjusted for age, sex, income, and number of contracted days. high job insecurity, a finding in line with earlier studies. ${ }^{11-13}$ However, in contrast to earlier work, ${ }^{811-13}$ health was unaffected by chronic job insecurity. There are several possible explanations for this. Unlike earlier job insecurity research, which focused on core employees, the present study focuses on the periphery of the workforce. Thus, it is possible that inconsistencies are the result of the context within which job insecurity occurs. ${ }^{36}$ For non-permanent workers job insecurity is an integral part of their work experiences. ${ }^{37}$ Workers accustomed to fixed term contracts may become more inured to job insecurity than workers on permanent contracts, ${ }^{3}$ for whom job insecurity involves a fundamental and involuntary change in their perceived position in the organisation. $^{37}$

Furthermore, the present results show that health risks of the working environment may come from somewhat different sources depending on employment status. Fixed term employees are more worried about the continuity of their job, but work overload is a greater burden for permanent staff.

Fixed term to permanent employees experienced lower job insecurity than those who remained on a fixed term contract, even before their transfer to permanent work. They were also more satisfied with their work than the rest of the fixed term workers. This result corresponds with earlier findings on selection from non-permanent to permanent employment. ${ }^{24}{ }^{38}$ Change from fixed term to permanent employment was followed by an increase in job security and job satisfaction, but other indicators of work, health, and health related behaviours remained unchanged. A ceiling effect is one possible cause for these results as fixed term to permanent employees were already relatively healthy at baseline.

Fixed term employees had less sickness absence than permanent employees, both at baseline and follow up, although job insecurity was significantly higher than in the other groups. This is likely, in part, to be the result of heath related selection into fixed term employment. However, this result is also compatible with the assumed "presenteeism" response to the threat of job loss, ${ }^{16}{ }^{20} 21$ which implies that job insecurity is one of the "presence factors" in fixed term work. ${ }^{39}$ In Finland, social security cover for sick leave is the same for both fixed term and permanent employees after one month's employment with the same employer.

Among fixed term to permanent employees, long term sickness absence spells had increased by follow up to the level seen among permanent staff. Job insecurity for these 
Table 3 Change in work characteristics, health, and health related behaviours for respondents by employment status

\begin{tabular}{|c|c|c|c|c|c|}
\hline & Fixed term & $\begin{array}{l}\text { p value for } \\
\text { difference }\end{array}$ & Fixed term to permanent & $\begin{array}{l}\text { p value for } \\
\text { difference }\end{array}$ & $\begin{array}{l}\text { Test of } \\
\text { heterogeneity } \\
\text { of differences }\end{array}$ \\
\hline \multicolumn{6}{|l|}{ Work } \\
\hline Workload & $-0.15(-0.28$ to -0.03$)$ & 0.014 & $-0.16(-0.43$ to 0.11$)$ & 0.323 & 0.320 \\
\hline Job insecurity & $1.87(1.76$ to 1.97$)$ & $<0.001$ & $0.07(-0.16$ to 0.29$)$ & 0.762 & $<0.001$ \\
\hline Job satisfaction & $-0.33(-0.46$ to -0.21$)$ & $<0.001$ & $0.22(-0.04$ to 0.48$)$ & 0.123 & 0.037 \\
\hline \multicolumn{6}{|c|}{0.00 1 o. } \\
\hline No. of diagnosed chronic diseases & $0.02(-0.15$ to 0.18$)$ & 0.964 & $-0.02(-0.37$ to 0.33$)$ & 0.994 & 0.798 \\
\hline Work ability & $0.29(0.07$ to 0.50$)$ & 0.006 & $0.21(-0.25$ to 0.67$)$ & 0.527 & 0.076 \\
\hline Minor psychiatric morbidity & $-0.19(-0.63$ to 0.25$)$ & 0.547 & $-0.50(-1.45$ to 0.45$)$ & 0.418 & 0.546 \\
\hline \multicolumn{6}{|l|}{ Health related behaviours } \\
\hline Alcohol intake (g/week) & $-10.31(-28.28$ to 7.67$)$ & 0.359 & $-3.23(-41.94$ to 35.48$)$ & 0.978 & 0.175 \\
\hline Smoking (no. of cigarettes/day) & $-0.09(-0.76$ to 0.59$)$ & 0.950 & $-0.38(-1.86$ to 1.10$)$ & 0.812 & 0.084 \\
\hline BMI & $0.34(-0.27$ to 0.94$)$ & 0.375 & $-0.20(-1.50$ to 1.10$)$ & 0.925 & 0.603 \\
\hline
\end{tabular}

Figures (adjusted for age, sex, and income) are differences in means $(95 \% \mathrm{Cl}$ ) and p values for differences at follow up and $\mathrm{p}$ values of analyses of variance for repeated measures for tests of heterogeneity of differences (in all cases the mean difference for permanent employment was set to 0.00 ). Tests of heterogeneity for employment status group differences between baseline and follow up were tested using the repeated measures analyses of variance procedure to determine the interaction between time and employment status.

employees decreased on transfer to permanent employment, possibly removing one of the "presence factors" that had depressed their level of sickness absence during fixed term employment. Furthermore, it is likely that any health related selection from fixed term to permanent employment will have worn off by follow up, ${ }^{40-42}$ although there is only slight evidence of this for the health indicators measured in this study.

\section{Methodological considerations}

We found that among the eligible population, change from fixed term to permanent employment was more common in men than in women, in higher income class than in lower income class, and in physicians than in other occupational groups. A similar difference was found among the respondents to the surveys with regard to sex only. Because of their higher socioeconomic status, non-respondents might have been healthier than others among the fixed term to permanent employees. ${ }^{43}$ In permanent employees, nonrespondents with lower socioeconomic status were overrepresented. This difference in attrition may slightly bias comparisons in health between fixed term to permanent employees and those with stable permanent jobs. The first group may in reality have better health than the latter group.

The longitudinal design of this study combined with data from employers' registers, national registers, and self completion questionnaires allowed us to avoid many problems due to common method variance, a bias artificially inflating associations between variables measured by self reports only. Furthermore, data from a prior period of insecure employment combined with reference groups of fixed term and permanent employees allowed us to make conclusions about the effect of change in employment status. However, the small sample size of fixed term to permanent employees may have led to a type II error and should be considered when making interpretations from non-significant effects.

Generalisability at the international level should also be considered with caution, as different national unemployment rates and employment regulations may moderate associations. The present cohort was comprised mainly of female healthcare workers, which limits the generalisability of the results to men and other occupations. However, besides nurses, hospitals employ a wide variety of workers from all levels of socioeconomic status, such as physicians, technicians, maintenance staff, cleaners, administrative staff, clerks, and secretaries, who make it equivalent to many other organisations.

\section{ACKNOWLEDGEMENTS}

This study was supported by the Finnish Work Environment Fund (FWEF) (project 97316) and the Academy of Finland (projects 44968 and 77560). JEF was supported by the Medical Research Council (grant number 47413) during the preparation of this paper.

\section{CONTRIBUTORS}

$M$ Virtanen, the principal investigator, conducted the analyses and was the principal author of the paper. M Kivimäki coordinated the project and helped with the data analyses. M Kivimäki, M Elovainio, J Vahtera and JE Ferrie contributed to the planning of the study design, interpretation of the results, and writing of the paper.

\section{Authors' affiliations}

M Virtanen, M Kivimäki, J Vahtera, Finnish Institute of Occupational Health, Department of Psychology, Topeliuksenkatu 41 a A, FIN-00250 Helsinki, Finland

M Elovainio, National Research and Development Centre for Welfare and Health, PO Box 220, 00531 Helsinki, Finland

J E Ferrie, Department of Epidemiology and Public Health, University College London, 1-19 Torrington Place, London WC1E 6BT, UK

\section{REFERENCES}

1 Letourneux V. Precarious employment and working conditions in the European Union. European Foundation for the Improvement of Living and Working Conditions. Luxembourg: Office for Official Publications of the European Communities, 1997.

2 Benavides FG, Benach J, Diez-Roug AV, et al. How do types of employment relate to health indicators? Findings from the Second European Survey on Working Conditions. J Epidemiol Community Health 2000;54:494-501.

3 Virtanen P, Vahtera J, Kivimäki $M$, et al. Employment security and health. J Epidemiol Community Health 2002;56:569-74.

4 Virtanen M, Kivimäki M, Elovainio M, et al. Contingent employment, health and sickness absence. Scand J Work Environ Health 2001;27:365-72.

5 Sverke M, Gallagher DG, Hellgren J. Job stress, well-being, and work attitudes among employees with different employment contracts. In: Isaksson $\mathrm{K}$, Hogstredt C, Eriksson C, Theorell T, eds. Health effects of the new labour market. New York: Kluwer Academic/Plenum Publishers, 2000: 145-67.

6 Martens MFJ, Nijhuis FJN, van Boxtel MPJ, et al. Flexible work schedules and mental and physical health. A study of a working population with nontraditional working hours. J Organ Behav 1999;20:35-46.

7 Klein Hesselink DJ, van Vuuren T. Job flexibility and job insecurity: the Dutch case. Eur J Work Organ Psychol 1999:8:273-93.

8 Heaney CA, Israel BA, House JS. Chronic job insecurity among automobile workers: effects on job satisfaction and health. Soc Sci Med 1994;38:1431-7.

9 Domenighetti G, D'Avanzo B, Bisig B. Health effects of job insecurity among employees in the Swiss general population. Int J Health Serv 2000;30:477-90.

10 Ferrie JE, Shipley MJ, Marmot MG, et al. Health effects of anticipation of job change and non-employment: longitudinal data from the Whitehall II study. BMJ 1995:311:1264-9.

11 Ferrie JE. Labour market status, insecurity and health. J Health Psychol 1997;2:373-97.

12 Ferrie JE, Shipley MJ, Marmot MG, et al. The health effects of major organisational change and job insecurity. Soc Sci Med 1998;46:243-54. 
13 Ferrie JE, Martikainen P, Shipley MJ, et al. Employment status and health after privatisation in white collar civil servants: prospective cohort study. $B M J$ 2001;322:647-51.

14 Mc Donough P. Job insecurity and health. Int J Health Serv 2000;30:453-76.

15 Aronsson G, Gustafsson K, Dallner M. Sick but yet at work. An empirical study of sickness presenteeism. J Epidemiol Community Health 2000;54:502-9.

16 Beale N, Nethercott S. Certificated sickness absence in industrial employees threatened with redundancy. BMJ 1988;296:1508-10.

17 Kivimäki M, Vahtera J, Thomson L, et al. Psychosocial factors predicting employee sickness absence during economic decline. J Appl Psychol 1997;82:858-72.

18 Kivimäki M, Vahtera J, Pentti J, et al. Factors underlying the effect of organisational downsizing on health of employees: longitudinal cohort study. BMJ 2000;320:971-5.

19 Vahtera J, Kivimäki M, Pentti J. Effect of organisational downsizing on health of employees. Lancet 1997;350:1124-8.

20 Virtanen P. "An epidemic of good health" at the workplace. Soc Health Illness 1994; 16:394-401.

21 Knutsson A, Goine H. Occupation and unemployment rates as predictors of long term sickness absence in two Swedish counties. Soc Sci Med 1998;47:25-31.

22 Sutela H, Vänskä J, Notkola V. Pätkätyöt Suomessa 1990-luvulla [Contingent employment in Finland in 1990s]. Työmarkkinat 1, Helsinki: Tilastokeskus, 2000;67:98

23 Statistics Finland. Tilastotietoa, Suomi lukuina, työelämä, työttömyys, 1998 [Statistics, Finland in Figures, Working life, Unemployment, 1998] http:// www.stat.fi/tk/tp/tasku/taskut/en.html. Searched 12 April 2001.

24 Virtanen $M$, Kivimäki $M$, Elovainio $M$, et al. Selection from fixed-term to permanent employment: prospective study on health, job satisfaction and behavioural risks. J Epidemiol Community Health 2002;56:693-9.

25 Harris PE. The Nurse Stress Index. Work Stress 1989:3:335-46.

26 Cooper CL, Mitchell S. Nurses under stress: a reliability and validity study of the NSI. Stress Med 1990;6:21-4.

27 Lehto A-M. Työelämän laatu ja tasa-arvo tuotannossa [The quality of working life and equality in production]. Helsinki: Tilastokeskus, 1991.

28 Hackman JR, Oldham GR. Development of the Job Diagnostic Survey. J Appl Psychol 1975;60:159-70.
29 Vahtera J, Uutela A, Pentti J. The effects of objective job demands on registered sickness absence spells: do personal, social and job-related resources act as moderators? Work Stress 1996;10:286-308.

30 Tuomi K, Ilmarinen J, Jahkola A, et al. Work Ability Index, 2nd revised edn. Occupational Health Care 19. Helsinki: Finnish Institute of Occupational Health, 1998.

31 Tuomi K, Huuhtanen P, Nykyri E, et al. Promotion of work ability, the quality of work and retirement. Occup Med 2001;51:318-24.

32 Goldberg DP. The detection of psychiatric illness by questionnaire Maudsley monograph no. 21. London: Oxford University Press, 1972.

33 Goldberg DP, Gater R, Sartorius N, et al. The validity of the two versions of the GHQ in the WHO study of mental illness in general health care. Psychol Med 1997;27:191-7.

34 SAS. Technical report P-243. SAS/STAT soffware: the genmod procedure, release 6.09. Cary, NC: SAS Institute Inc, 1993.

35 Cohen J, Cohen P. Applied multiple regression/correlation analysis for the behavioral sciences. Erlbaum, NJ: Hillsdale, 1983.

36 Benach J, Amable M, Muntaner C, et al. The consequences of flexible work for health: are we looking at the right place? J Epidemiol Community Health 2002;56:405-6.

37 Hartley J, Jacobson D, Klandermans B, et al. Job insecurity: coping with jobs at risk. London: Sage Publications Ltd, 1991.

38 Baver T, Truxillo D. Temp-to-permanent employees: a longitudinal study of stress and selection success. J Occup Health Psychol 2000;5:337-46.

39 Kristensen TS. Sickness absence and work strain among Danish slaughterhouse workers: an analysis of absence from work regarded as coping behaviour. Soc Sci Med 1991;32:15-27.

40 McMichael AJ. Standardized mortality ratios and the "healthy worker effect": scratching beneath the surface. J Occup Med 1976;18:165-8.

41 Fox AJ, Collier PF. Low mortality rates in industrial cohort studies due to selection for work and survival in the industry. Br J Prev Soc Med 1976;30:225-30.

42 Carpenter LM. Some observations on the healthy worker effect. $\mathrm{Br} J$ Ind Med 1987;44:289-91.

43 Marmot MG, Davey Smith G, Stansfeld S, et al. Health inequalities among British civil servants: the Whitehall II study. Lancet 1991;337:1387-93. 